\title{
FLUORESCENT DISPERSE DYES: REFLECTANCE SPECTRA, RELATIVE STRENGTH AND PERFORMANCE EVALUATION OF COUMARIN CLASS ON POLYESTER/COTTON BLENDED FABRIC
}

\author{
Nawshin Farzana ${ }^{1}$ \\ ${ }^{1}$ Lecturer, Department of Textile Engineering, Daffodil International University, Dhaka, Bangladesh
}

\begin{abstract}
This study attempted to focus on some important properties of regular fluorescent disperse dyes on polyester/cotton fabric. A $60 / 40 \mathrm{p} / \mathrm{c}$ blended woven fabric was used to dye only the polyester part in pad-thermosol dyeing process (continuous method) with different concentrations of fluorescent disperse dyes. The selected dyestuff was Terasil Flavine 10GFF belonging to coumarin class of fluorescent dye. This paper mainly aims to investigate Spectral parameters such as Reflectance curve, K/S values (with Kubelka-Munk equation) and Relative strength percentage with different concentrations of fluorescent dyes. Different color fastness properties like wash, water, rubbing, perspiration and light fastness were also assessed to evaluate performance of polyester substrate dyed with fluorescent dyes.
\end{abstract}

Keywords: Fluorescence, disperse dye, pad-thermosol dyeing, reflectance, $k / s$ value, relative strength, color fastness.

\section{INTRODUCTION}

The applications of fluorescent textiles are associated with their ability to attract attention, because of the remarkable vivid brilliance of the colors which results from the extra glow of emitted fluorescent light [1].

Fluorescent fabrics may be used for specific aesthetic and fashion purposes, the eye-catching bright colors providing unique creative opportunities for the textile and garment designer. They are also used for functional reasons, assuming special importance in leisurewear, sportswear and work wear. Police, firefighters and other emergency services personnel, and construction workers who require visibility in their work surroundings wear garments with fluorescent colors [2].

Fluorescent dyes have been defined as compounds which both absorb and also emit strongly in the visible region of the electromagnetic spectrum, and which owe their potentials application to their intense fluorescence properties [3].
Fluorescent dyes are of much greater importance for application to synthetic fibers such as polyester, polyamides and polyacrylonitrile, sometimes also in conjunction with elastane fibers. The most important textile applications are on polyester and thus the most important fluorescent textile dyes are from the disperse dye class. [2]

An interesting publication analyses the market for fluorescent dyes in Poland and assesses the suitability of the commercially available yellow dyes to meet the requirements of the European standard (EN 471:1997) for high visibility 'warning' clothing [4].

Fluorescent dyes to be of practical use must produce a pure color dictated by their absorption and emission spectra [5].The absorption and emission spectra of a fluorescent dye often approximate to mirror images of one another as illustrated in Fig 1 [2]. The difference between the absorption and emission wavelength maxima is referred to as the Stokes shift (described by Sir Jorge Gabriel Stokes).

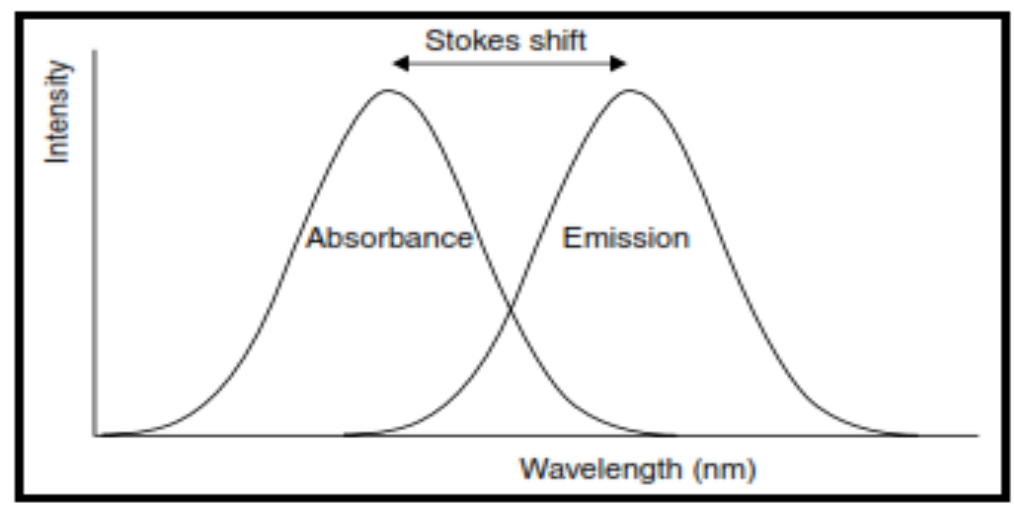

Fig.1 Absorption and emission spectra of a typical yellow fluorescent dye 
Coumarin derivatives provide the most important industrial fluorescent dyes. Fluorescent coumarins are known which absorb and emit in most parts of the visible spectrum, although most commercial products are yellow with a green fluorescence. This group provides important disperse dyes which allow synthetic fibers, especially polyester, to be dyed in brilliant fluorescent greenish -yellow shades. [2]

A general structure of coumarin class of fluorescent dye of commercial importance is given in the Fig-2 [1].

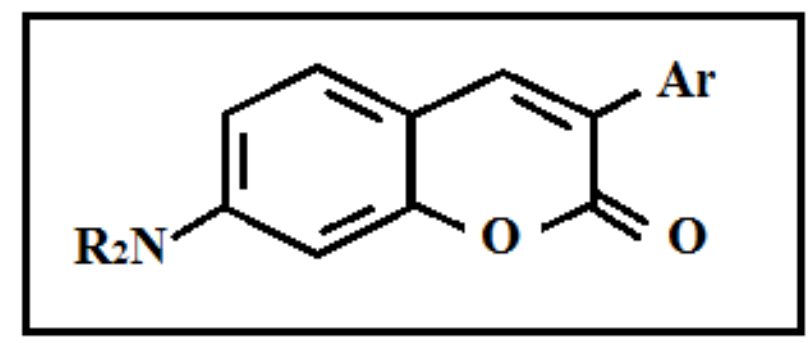

Fig 2: Coumarin class of Fluorescent dye

This paper mainly focuses on the study of some spectral properties specifically relative strength of dyes with reflectance and $\mathrm{k} / \mathrm{s}$ values with varying dye concentrations (shade percentage) of fluorescent disperse dye of cuomarin class. The commercial fluorescent dyes recommended for textiles are often criticized for light fastness properties which are unable to meet the standards required by more demanding applications. This paper also aims to evaluate different color fastness properties such as wash, water, perspiration, rubbing including light fastness of coumarin class of dyes.

\section{MATERIAL \& METHODS}

\subsection{Material (Fabric)}

Woven desized, scoured and bleached P/C fabrics were used for this experiment to dye (only the polyester part) in padthermosol dyeing process (continuous method) with different concentrations in gram per liter ( $\mathrm{gpl}$ ) of fluorescent disperse dye. The specifications of fabrics are given in Table 1.

Table:1 Fabric specifications

\begin{tabular}{|l|l|}
\hline Parameters & $\begin{array}{l}\text { Desized-Scoured-Bleached } \\
\text { Fabric }\end{array}$ \\
\hline Structure & Woven (poplin) \\
\hline Composition & Polyester/Cotton blended \\
\hline Blend percentage & $60 / 40$ \\
\hline Ends/inch & 110 \\
\hline Picks/inch & 73 \\
\hline Warp count & 45 \\
\hline Weft count & 45 \\
\hline GSM & 95 \\
\hline
\end{tabular}

\subsection{Method}

\subsubsection{Dyeing Procedure (Pad-Dry-Thermosol}

\section{Method)}

Terasil Flavine 10 GFF fluorescent disperse dye (Huntsman) was collected from swiss colour, Bangladesh. Pad-thermosol dyeing [7] procedure was adopted to dye the fabric samples. 8 pieces of pretreated blended $\mathrm{p} / \mathrm{c}$ samples were padded in the dye bath using laboratory padding mangle of each concentration separately for both classes of dyes. After padding the samples were dried thoroughly and cured in the laboratory dryer. The dye bath set-up, drying and curing conditions are given in Table 2

Table: 2 Dyeing parameters

\begin{tabular}{|l|l|}
\hline Fluorescent dye (disperse) & Terasil Flavine 10 GFF \\
\hline Chemical class & coumarin \\
\hline Dye concentrations, gpl & $1,3,5,10,20,30,40,50$ \\
\hline Dispersing agent, gpl & 2 \\
\hline Sequestering agent, gpl & 1 \\
\hline Anti-migrant, gpl & 20 \\
\hline Acetic acid, gpl & 0.5 \\
\hline pH & 5.5 \\
\hline Wet pick-up \% & 60 \\
\hline Drying temperature, ${ }^{\circ} \mathrm{C}$ & 130 \\
\hline Drying time, sec & 120 \\
\hline Curing temperature, ${ }^{\circ} \mathrm{C}$ & 220 \\
\hline Curing time, sec & 90 \\
\hline
\end{tabular}

\subsubsection{After-Treatments}

Reduction cleaning [8] was done manually after curing for every samples taking in a beaker separately with $500 \mathrm{ml}$ solutions with the chemicals and parameters listed in table 3 .

Table 3: Reduction cleaning

\begin{tabular}{|l|l|}
\hline Alkali (Caustic soda, NaOH), gpl & 2 \\
\hline $\begin{array}{l}\text { Hydros (Sodium hydro Sulphite, Na2S2O4), } \\
\text { gpl }\end{array}$ & 2 \\
\hline Liquor temperature, ${ }^{\circ} \mathrm{C}$ & 70 \\
\hline Treatment time, min & 20 \\
\hline
\end{tabular}

Then all of the samples were treated according to the flow chart-

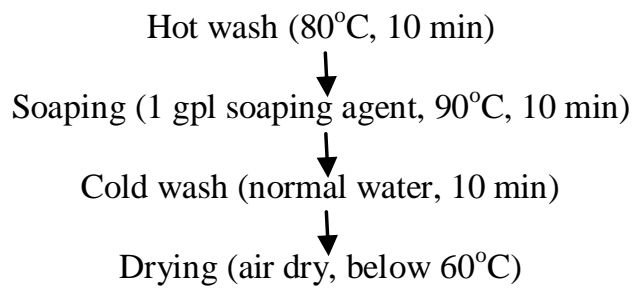




\subsubsection{Spectral Measurement Procedure}

Reflectance values and curves of the dyed fabrics were determined in the visible portion of the spectrum (400-700 $\mathrm{nm}$ ) using a reflectance spectrophotometer (Datacolor 650) and the standard illuminant was D65 with $10^{\circ}$ observer. The measurements were taken in four different places making four folds of each samples and their average was taken for the analysis of each result. K/S values of the minimum reflectance value were obtained using the Kubelka-Munk equation [9]:

\section{$K / S=(1-R)^{2} / 2 R$}

$\mathrm{K} / \mathrm{S}=$ absorption function

$\mathrm{R}=$ minimum reflectance value at a wavelength of maximum absorption

The color strength values (\%) of samples were determined in comparison to the deepest dyeing ( $50 \mathrm{gpl}$ dyed sample) as $100 \%$ color strength by using the following equation:

$$
\% \text { Strength }=\frac{K / S_{(\text {sample })}}{K / S_{(\text {standard })}} \times 100
$$

\subsubsection{Evaluation of Color Fastness of Dyed Samples}

Different color fastness properties of the dyed samples were assessed according to the following methods:

- $\quad$ Color fastness to wash (ISO 105 C06) [10]

- Color fastness to water (ISO 105 E01) [11]

- Color fastness to perspiration (ISO 105 E04) [12]

- Color fastness to rubbing (ISO 105 X12) [13]

- Color fastness to light (mercury vapour lamp, 72 hrs)

Color fastness (wash, water, perspiration, rubbing) were assessed using Grey Scale on a rating of 1 to 5 where (rating $5 \& 1$ describe excellent and very poor respectively) and light fastness was evaluated using Blue Wool Standard Scale on a rating of 1 to 8 whereas (rating $8 \& 1$ describe outstanding and very poor respectively).

\section{RESULTS \& DISCUSSION}

\subsection{Spectral Data Analysis}

\subsubsection{Reflectance Data in the Visible Spectra}

Table-4: Spectral value of Terasil Flavine $10 \mathrm{GFF}$

\begin{tabular}{|l|l|l|l|}
\hline $\begin{array}{l}\text { Dye Conc. } \\
\text { gpl }\end{array}$ & $\begin{array}{l}\mathbf{R} \% \\
\text { min } \\
\text { (approx) }\end{array}$ & $\mathbf{K} / \mathbf{S}=(\mathbf{1 - R})^{\mathbf{2}} / \mathbf{2 R}$ & $\begin{array}{l}\text { Relative } \\
\text { Strength\% }\end{array}$ \\
\hline 1 & 25.39 & 1.1 & 22.6 \\
\hline 3 & 20.85 & 1.5 & 30.9 \\
\hline 5 & 18.5 & 1.8 & 37 \\
\hline 10 & 14.45 & 2.53 & 52.1 \\
\hline 20 & 11.2 & 3.52 & 72.5 \\
\hline 30 & 9.8 & 4.15 & 85.5 \\
\hline 40 & 9 & 4.6 & 94.7 \\
\hline 50 & 8.6 & 4.86 & 100 \\
\hline
\end{tabular}

Table 4 represents the reflectance percentage $(\% \mathrm{R})$ of Terasil Red 3BFF dyes of different concentrations at every $10 \mathrm{~nm}$ intervals of wavelength over the visible region $(400-700 \mathrm{~nm})$. The wavelength of minimum and maximum reflectance were observed at 440 $\mathrm{nm}$ and $510 \mathrm{~nm}$ respectively.

Table.5 \% Reflectance of Terasil Flavine 10GFF on visible spectrum

\begin{tabular}{|l|l|l|l|l|l|l|l|l|}
\hline \multirow{2}{*}{\begin{tabular}{l}
$\boldsymbol{n} \mathbf{n m}$ \\
\cline { 2 - 9 }
\end{tabular}} & \multicolumn{6}{|}{ \% Reflectance } \\
\hline $\mathbf{g p l}$ & $\mathbf{3}$ gpl & $\mathbf{5}$ gpl & $\begin{array}{l}\mathbf{1 0} \\
\text { gpl }\end{array}$ & $\begin{array}{l}\mathbf{2 0} \\
\text { gpl }\end{array}$ & $\begin{array}{l}\mathbf{3 0} \\
\text { gpl }\end{array}$ & $\begin{array}{l}\mathbf{4 0} \\
\text { gpl }\end{array}$ & $\begin{array}{l}\mathbf{5 0} \\
\text { gpl }\end{array}$ \\
\hline 400 & 33.2 & 29.6 & 23.3 & 17.8 & 16.1 & 15.5 & 13.0 & 11.7 \\
\hline 410 & 31.1 & 25.7 & 21.4 & 17.0 & 14.4 & 14.1 & 12.5 & 11.0 \\
\hline 420 & 27.7 & 23.5 & 20.8 & 16.0 & 13.4 & 12.4 & 11.4 & 10.0 \\
\hline 430 & 25.5 & 21.7 & 19.8 & 15.2 & 12.3 & 10.3 & 10.2 & 8.5 \\
\hline 440 & 25.4 & 20.9 & 18.5 & 14.5 & 11.2 & 9.8 & 9.0 & 8.6 \\
\hline
\end{tabular}




\begin{tabular}{|l|l|l|l|l|l|l|l|l|}
\hline 450 & 24.8 & 21.6 & 18.2 & 15.1 & 12.0 & 10.0 & 9.2 & 8.5 \\
\hline 460 & 27.8 & 23.0 & 19.8 & 17.4 & 12.6 & 10.6 & 9.8 & 9.2 \\
\hline 470 & 32.7 & 28.4 & 20.2 & 19.8 & 14.0 & 12.4 & 10.2 & 11.2 \\
\hline 480 & 54.2 & 38.0 & 26.5 & 26.7 & 18.7 & 14.5 & 13.1 & 13.1 \\
\hline 490 & 85.7 & 70.6 & 52.3 & 41.0 & 30.5 & 28.8 & 22.4 & 21.7 \\
\hline 500 & 118.3 & 117.4 & 98.6 & 83.1 & 50.3 & 47.0 & 45.8 & 44.3 \\
\hline 510 & 125.8 & 126.0 & 126.6 & 122.4 & 121.4 & 120.9 & 122.0 & 125.0 \\
\hline 520 & 122.1 & 125.2 & 128.4 & 134.0 & 138.1 & 139.9 & 140.5 & 142.5 \\
\hline 530 & 114.4 & 120.3 & 126.7 & 130.1 & 133.0 & 135.1 & 137.0 & 139.8 \\
\hline 540 & 106.2 & 111.1 & 119.1 & 118.0 & 119.4 & 121.8 & 124.0 & 129.8 \\
\hline 550 & 100.5 & 105.4 & 110.4 & 109.4 & 112.0 & 116.0 & 115.0 & 117.3 \\
\hline 560 & 95.6 & 98.3 & 102.8 & 103.0 & 105.2 & 107.2 & 108.0 & 109.6 \\
\hline 570 & 92.1 & 94.1 & 97.5 & 99.7 & 100.8 & 102.3 & 103.8 & 105.2 \\
\hline 580 & 89.5 & 91.0 & 93.4 & 96.2 & 97.4 & 98.1 & 99.0 & 101.8 \\
\hline 590 & 87.4 & 88.7 & 90.1 & 92.7 & 93.8 & 94.4 & 96.3 & 98.7 \\
\hline 600 & 86.2 & 87.5 & 88.3 & 90.8 & 91.6 & 92.9 & 93.8 & 95.8 \\
\hline 610 & 85.5 & 86.1 & 86.9 & 89.2 & 89.8 & 90.2 & 92.0 & 93.1 \\
\hline 620 & 85.1 & 85.5 & 85.8 & 87.7 & 88.1 & 89.5 & 90.0 & 91.4 \\
\hline 630 & 85.3 & 85.4 & 85.7 & 87.5 & 87.6 & 88.2 & 88.8 & 89.1 \\
\hline 640 & 85.6 & 85.6 & 85.6 & 87.3 & 87.4 & 87.5 & 88.1 & 88.8 \\
\hline 650 & 85.8 & 85.6 & 85.6 & 86.9 & 86.7 & 86.8 & 87.0 & 88.7 \\
\hline 660 & 86.1 & 85.9 & 85.7 & 87.1 & 86.4 & 86.4 & 87.1 & 87.5 \\
\hline 670 & 86.3 & 86.1 & 85.9 & 86.9 & 86.6 & 86.4 & 86.4 & 87.5 \\
\hline 680 & 86.4 & 85.6 & 85.9 & 86.9 & 86.3 & 86.4 & 86.4 & 86.4 \\
\hline 690 & 86.4 & 86.2 & 85.9 & 86.8 & 86.6 & 86.2 & 86.4 & 86.4 \\
\hline 700 & 86.6 & 87.0 & 86.2 & 86.9 & 86.4 & 86.3 & 86.4 & 87.4 \\
\hline
\end{tabular}

Table 5 represents the reflectance percentage of Terasil Flavine 10 GFF dyes of different concentrations at every $10 \mathrm{~nm}$ intervals of wavelength over the visible region (400-700nm). 


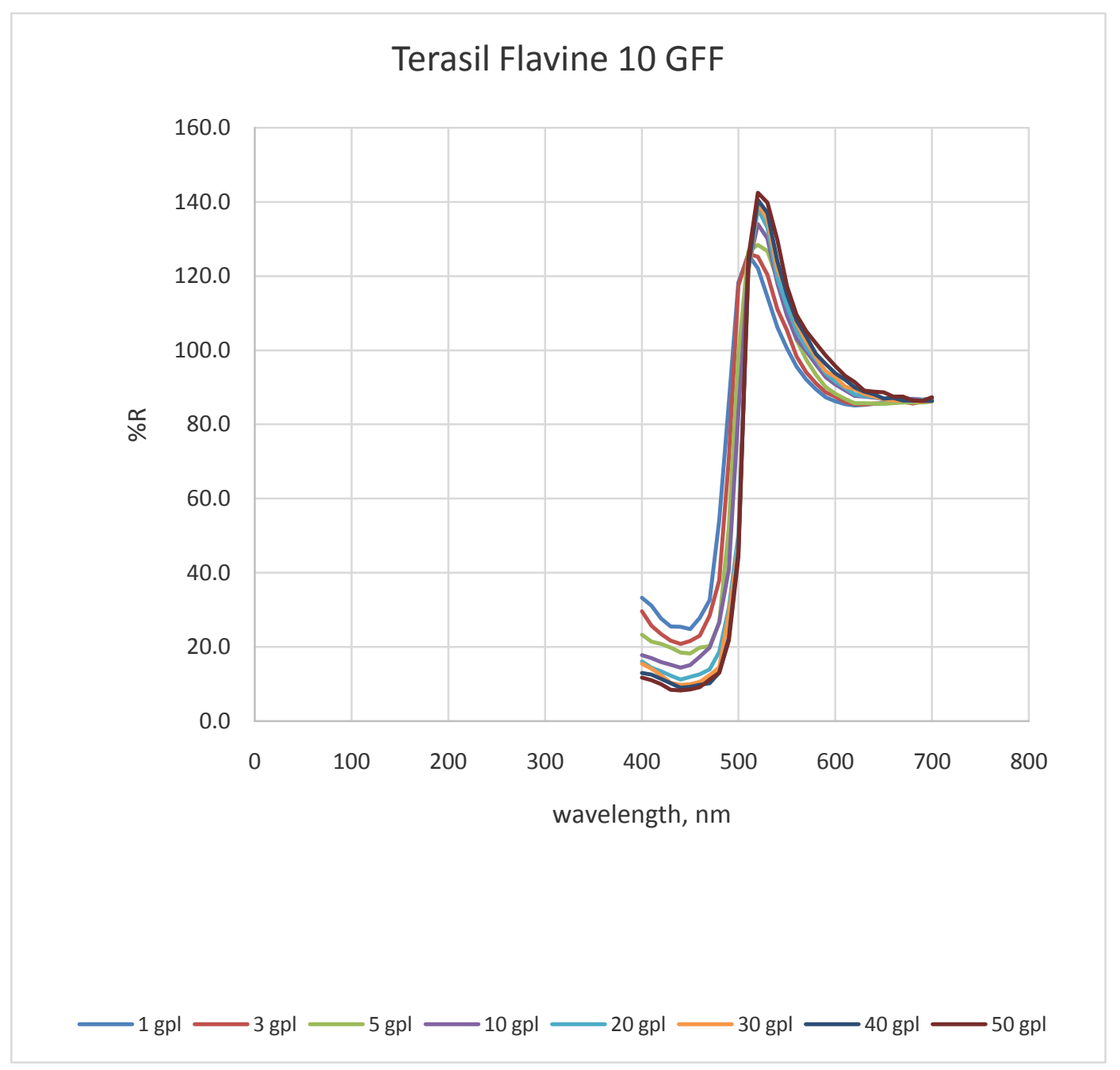

Fig.3 Reflectance curve of Terasil Flavie 10 GFF

The wavelength of minimum and maximum reflectance were $10-28 \%$ and $122-142 \%$ observed at $440 \mathrm{~nm}$ and $520 \mathrm{~nm}$ respectively throughtout the concentrations of fluorescent dyes. A reflectance curve was also constructed with wavelength with all concentrations of dyes showing in fig.3.

\subsection{Color Fastness Evaluation}

Table 6: Color Fastness to wash

\begin{tabular}{|l|l|l|l|l|l|l|l|}
\hline $\begin{array}{l}\text { Dye } \\
\text { conc } \\
\text { gpl }\end{array}$ & $\begin{array}{l}\text { color } \\
\text { change }\end{array}$ & \multicolumn{2}{|l|}{ staining } \\
\cline { 3 - 8 } & & AC & CO & NL & PES & AR & WL \\
\hline 1 & $4-5$ & $4-5$ & $4-5$ & $4-5$ & $4-5$ & $4-5$ & $4-5$ \\
\hline 3 & $4-5$ & $4-5$ & $4-5$ & 4 & $4-5$ & $4-5$ & $4-5$ \\
\hline 5 & $4-5$ & $4-5$ & $4-5$ & $3-4$ & $4-5$ & $4-5$ & $4-5$ \\
\hline 10 & $4-5$ & 4 & $4-5$ & 3 & $4-5$ & $4-5$ & $4-5$ \\
\hline 20 & $4-5$ & 4 & $4-5$ & 3 & $4-5$ & $4-5$ & $4-5$ \\
\hline 30 & $4-5$ & $3-4$ & 4 & $2-3$ & 4 & $4-5$ & $4-5$ \\
\hline 40 & 4 & 3 & 4 & $2-3$ & 4 & 4 & 4 \\
\hline 50 & 4 & 3 & 4 & 2 & 4 & 4 & 4 \\
\hline
\end{tabular}

Table 6 -10 illustrate the grades color fastness to wash, water, perspiration, rubbing and light fastness respectively.

AC(acetate), CO (cotton), NL (nylon), PES (polyester), AR (acrylic),WL (wool) staining were assessed with DW multifibre fabric. 
Table-7: Color Fastness to Water

\begin{tabular}{|l|l|l|l|l|l|l|l|}
\hline $\begin{array}{l}\text { Dye } \\
\text { conc. } \\
\text { gpl }\end{array}$ & $\begin{array}{l}\text { color } \\
\text { change }\end{array}$ & \multicolumn{6}{|l|}{ staining } \\
\cline { 3 - 8 } & & AC & CO & NL & PES & AR & WL \\
\hline 1 & $4-5$ & $4-5$ & $4-5$ & $4-5$ & $4-5$ & $4-5$ & $4-5$ \\
\hline 3 & $4-5$ & $4-5$ & $4-5$ & 4 & $4-5$ & $4-5$ & $4-5$ \\
\hline 5 & $4-5$ & 4 & $4-5$ & $3-4$ & $4-5$ & $4-5$ & $4-5$ \\
\hline 10 & $4-5$ & 4 & 4 & 3 & $4-5$ & $4-5$ & $4-5$ \\
\hline 20 & $4-5$ & $3-4$ & 4 & 3 & 4 & $4-5$ & 4 \\
\hline 30 & $4-5$ & $3-4$ & 4 & $2-3$ & 4 & $4-5$ & 4 \\
\hline 40 & 4 & 3 & $3-4$ & 2 & $3-4$ & 4 & $3-4$ \\
\hline 50 & 4 & 3 & $3-4$ & 2 & 3 & 4 & $3-4$ \\
\hline
\end{tabular}

Table-8a: Color Fastness to Acid Perspiration

\begin{tabular}{|l|l|l|l|l|l|l|l|}
\hline \multirow{2}{*}{$\begin{array}{l}\text { Dye } \\
\text { conc. } \\
\text { gpl }\end{array}$} & $\begin{array}{l}\text { color } \\
\text { change }\end{array}$ & \multicolumn{6}{|l|}{ staining (acid) } \\
\cline { 2 - 8 } & & AC & CO & NL & PES & AR & WL \\
\hline 1 & $4-5$ & $4-5$ & $4-5$ & $4-5$ & $4-5$ & $4-5$ & $4-5$ \\
\hline 3 & $4-5$ & $4-5$ & $4-5$ & 4 & $4-5$ & $4-5$ & $4-5$ \\
\hline 5 & $4-5$ & $4-5$ & $4-5$ & $3-4$ & $4-5$ & $4-5$ & $4-5$ \\
\hline 10 & $4-5$ & 4 & $4-5$ & 3 & $4-5$ & $4-5$ & $4-5$ \\
\hline 20 & $4-5$ & 4 & 4 & 3 & $4-5$ & $4-5$ & $4-5$ \\
\hline 30 & 4 & $3-4$ & 4 & $2-3$ & 4 & 4 & $4-5$ \\
\hline 40 & 4 & $3-4$ & $3-4$ & $2-3$ & 4 & 4 & 4 \\
\hline 50 & 4 & 3 & $3-4$ & 2 & $3-4$ & 4 & 4 \\
\hline
\end{tabular}

Table-8b: Color Fastness to Alkali Perspiration

\begin{tabular}{|l|l|l|l|l|l|l|l|}
\hline \multirow{2}{*}{$\begin{array}{l}\text { Dye } \\
\text { conc. } \\
\text { gpl }\end{array}$} & \multirow{2}{*}{$\begin{array}{c}\text { color } \\
\text { change }\end{array}$} & \multicolumn{7}{|l|}{} \\
\cline { 3 - 8 } staining (alkali) \\
\cline { 3 - 8 } & & AC & CO & NL & PES & AR & WL \\
\hline 1 & $4-5$ & $4-5$ & $4-5$ & $4-5$ & $4-5$ & $4-5$ & $4-5$ \\
\hline 3 & $4-5$ & $4-5$ & $4-5$ & $4-5$ & $4-5$ & $4-5$ & $4-5$ \\
\hline 5 & $4-5$ & $4-5$ & $4-5$ & 4 & $4-5$ & $4-5$ & $4-5$ \\
\hline 10 & $4-5$ & 4 & $4-5$ & 4 & $4-5$ & $4-5$ & $4-5$ \\
\hline 20 & $4-5$ & 4 & $4-5$ & $3-4$ & 4 & 4 & $4-5$ \\
\hline 30 & 4 & $3-4$ & 4 & $3-4$ & 4 & 4 & 4 \\
\hline 40 & 4 & 3 & $3-4$ & 3 & $3-4$ & 4 & 4 \\
\hline 50 & 4 & 3 & $3-4$ & 3 & $3-4$ & 4 & 4 \\
\hline
\end{tabular}

No remarkable change found after wash for all the classes of dyes, poor staining rating to nylon was noticed for higher concentrations of dyes otherwise slight staining was found for other concentrations (Table-6).Change in color after water treatment showed good fastness rating throughout all concentrations for dyes, poor nylon staining was found with higher concentration otherwise moderate to good (Table-7).

Slight change in depth were found for overall dye concentrations in both Acid \& Alkali medium, The dye stained in acid more than in alkali to acetate, cotton, acrylic specially nylon with highest concentrations used (Table-8).
Table-9: Color Fastness to Rubbing

\begin{tabular}{|l|l|l|l|}
\hline \multirow{2}{*}{$\begin{array}{l}\text { Dye conc. } \\
\text { gpl }\end{array}$} & \multirow{2}{*}{$\begin{array}{c}\text { color } \\
\text { change }\end{array}$} & \multicolumn{2}{|l|}{ staining } \\
\cline { 3 - 4 } & & dry & wet \\
\hline 1 & $4-5$ & $4-5$ & $4-5$ \\
\hline 3 & $4-5$ & $4-5$ & 4 \\
\hline 5 & $4-5$ & $4-5$ & 4 \\
\hline 10 & $4-5$ & $4-5$ & 4 \\
\hline 20 & $4-5$ & 4 & $3-4$ \\
\hline 30 & $4-5$ & 4 & $3-4$ \\
\hline 40 & 4 & 4 & 3 \\
\hline 50 & 4 & 4 & 3 \\
\hline
\end{tabular}


The results of rubbing test indicated overall strong staining in dry state and moderate staining resulted in wet rubbing (Table-9).The light fastness exceptionally resulted in strong fading with increasing concentrations (for dark shades) whereas light concentrations exhibited good photo stability (Table-10).

Table-10: Color Fastness to Light

\begin{tabular}{|l|l|}
\hline $\begin{array}{l}\text { Dye conc. } \\
\text { gpl }\end{array}$ & Fading \\
\hline 1 & 7 \\
\hline 3 & 6 \\
\hline 5 & 6 \\
\hline 10 & 5 \\
\hline 20 & 5 \\
\hline 30 & 4 \\
\hline 40 & 3 \\
\hline 50 & 3 \\
\hline
\end{tabular}

\section{CONCLUSION}

Accurate characterisation of a fluorescent surface requires a bispectral instrument with two monochromators [14] but this spectral measurements were performed with traditional spectrophotometer which was available in industrial dyeing laboratory. Hence The results may vary slightly from the actual. The minimum and maximum reflectance of the luminous yellow shade was found in $440 \mathrm{~nm}$ and $520 \mathrm{~nm}$ respectively from the emission spectra. Maximum absorption value was considered for minimum reflection from reflection spectra only as absorption spectra was not constructed. There was a sharp increase in strength with increasing concentrations of dye up to $30 \mathrm{gpl}$ dye concentration indicating $85 \%$ as compared to that incase of $50 \mathrm{gpl}$. Strong color fastness resulted for wash, water and perspiration but poor nylon staining was caused in every case for higher concentrations. Both dry and wet rubbing was good enough. Exceptional results for light fastness indicated significant fading in case of darker shades which was unusual to regular textile dyes behavior.

\section{ACKNOWLEDGEMENTS}

The author gratefully acknowledges the support from Bextex Ltd., Gazipur, Bangladesh.

\section{REFERENCES}

[1]. Higgins SD, Towns A D, "Standing out in a crowd: Fluorescence and fluorescent dyes", Chimica Oggi (Chemistry Today), 2003

[2]. R. M. Christie, "Handbook of Textile and Industrial Dyeing", Heriot-Watt University, UK, Woodhead Publishing Ltd, chapter 17, 2011, pp: 577

[3]. R. M. Christie, "Fluorescent Dyes", Review of progress in coloration, 1993, vol 23, pp:1-18

[4]. Szuster L, Kazmierska M, Krol I, "Fluorescent dyes destined for dyeing high-visibility polyester textile products", Fibres and Textiles in Eastern Europe, 2004, vol 12, pp: $70-75$
[5]. Hunger K, "Industrial dyes: Chemistry, Properties, Applications", Wiley-VCH, New York, USA, 2003

[6]. Springsteen A, "Introduction to the measurement of color of fluorescent material", Analytica Chimia Acta, 1999, vol 380, pp:183-192

[7]. J. R. Aspland, "Textile Dyeing and Coloration", American Association of Textile Chemists and Colorists, 1997, pp: 186

[8]. Arthur D Broadbent, "The Basic Principles of Textile Coloration", Society of Dyers \& Coorists, 2001, pp:325

[9]. Peters, R.H. "The Physical Chemistry of Dyeing", Elsevier Scientific Publications Company, 1975

[10]. ISO 105 C06: Textiles -- Tests for colour fastness -Part C06: Colour fastness to domestic and commercial laundering, 2010

[11]. ISO 105 E01: Textiles -- Tests for colour fastness -Part E01: Colour fastness to water, 2013

[12]. ISO 105 E04: Textiles -- Tests for colour fastness -Part E04: Colour fastness to perspiration, 2013

[13]. ISO 105 X12: Textiles -- Tests for colour fastness -Part X12: Colour fastness to rubbing, 2001

[14]. Aspland J R, "Whither textile colour application research?", Dyes and Pigments, 2000

\section{BIOGRAPHY}

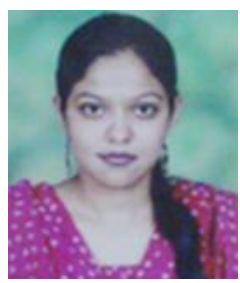

Nawshin Farzana had completed her graduation from College of Textile Technology, University of Dhaka. She is currently doing her research in MSc in Textile Wet Processing Engineering at Bangladesh University of Textiles. She worked in the department of Lab and QA at Beximco Textile Division (Bextex Ltd.) for 3 years and has an experience of teaching for about 6 years. 